\title{
Therapeutic Effects of Cystamine in a Murine Model of Huntington's Disease
}

\author{
Alpaslan Dedeoglu, ${ }^{1,2}$ James K. Kubilus, ${ }^{1,2}$ Thomas M. Jeitner, ${ }^{2,4}$ Samantha A. Matson, ${ }^{2}$ Misha Bogdanov, ${ }^{3,5}$ \\ Neil W. Kowall,, ${ }^{1,2}$ Wayne R. Matson, ${ }^{3}$ Arthur J. L. Cooper, ${ }^{4,5,6}$ Rajiv R. Ratan, ${ }^{7}$ M. Flint Beal, ${ }^{\star *}$ \\ Steven M. Hersch, ${ }^{8 *}$ and Robert J. Ferrante ${ }^{1,2}$ \\ ${ }^{1}$ Geriatric Research Education and Clinical Center, Bedford Veterans Affairs Medical Center, Bedford, Massachusetts \\ 01730, 2Neurology, Pathology, and Psychiatry Departments, Boston University School of Medicine, Boston, \\ Massachusetts 02118, ${ }^{3} E S A$ Laboratories, Inc., Chelmsford, Massachusetts 01824, Departments of ${ }^{4}$ Biochemistry and \\ 5 Neurology and Neuroscience, Weill Medical College of Cornell University, Presbyterian Hospital, New York, New York \\ 10021, ${ }^{6}$ Burke Medical Research Institute, White Plains, New York 10605, ${ }^{7}$ Department of Neurology and Program in \\ Neuroscience, Harvard Medical School and The Beth Israel-Deaconess Medical Center, Boston, Massachusetts 02115, \\ and ${ }^{8}$ Center for Aging, Genetics, and Neurodegeneration, Neurology Service, Massachusetts General Hospital and \\ Harvard Medical School, Boston, Massachusetts 02129
}

The precise cause of neuronal death in Huntington's disease $(\mathrm{HD})$ is unknown. Proteolytic products of the huntingtin protein can contribute to toxic cellular aggregates that may be formed in part by tissue transglutaminase (Tgase). Tgase activity is increased in HD brain. Treatment in R6/2 transgenic HD mice, using the transglutaminase inhibitor cystamine, significantly extended survival, improved body weight and motor performance, and delayed the neuropathological sequela. Tgase activity and $N^{\Sigma}-(\gamma$-L-glutamyl)-L-lysine (GGEL) levels were significantly altered in HD mice. Free GGEL, a specific biochemical marker of Tgase activity, was markedly elevated in the neocortex and caudate nucleus in HD patients. Both Tgase and GGEL immunoreactivities colocalized to huntingtin aggregates. Cystamine treatment normalized transglutaminase and GGEL levels in R6/2 mice. These findings are consistent with the hypothesis that transglutaminase activity may play a role in the pathogenesis of HD, and they identify cystamine as a potential therapeutic strategy for treating HD patients.

Key words: Huntington's disease; cystamine; transglutaminase; glutamyl lysine; neuroprotection; transgenic R6/2 mice
The disease phenotype in Huntington's disease (HD) is caused by an expansion of a polyglutamine tract in the protein, huntingtin (htt) (Huntington's Disease Collaborative Research Group, 1993), leading to conformational change, abnormal protein-protein interactions, and eventual neuronal death. Mutant htt undergoes proteolytic processing, in part by the pro-apoptotic enzyme caspase-3, releasing an N-terminal fragment containing the polyglutamine tract (Goldberg et al., 1996). This fragment forms macromolecular aggregates with itself and other proteins that become ubiquitinated and large enough to be visible in the processes, cytoplasm, and nuclei of neurons (Davies et al., 1997; DiFiglia et al., 1997; Scherzinger et al., 1997; Kuemmerle et al., 1999). Aggregation of the N-terminal fragments of huntingtin is CAG-length dependent, occurring once the polyglutamine tract is $>36$ amino acids long and increases with greater lengths ( $\mathrm{Li}$ and Li, 1998; Martindale et al., 1998). Thus, it has been hypoth-

Received June 14, 2002; revised July 30, 2002; accepted Aug. 2, 2002.

This work was supported by National Institutes of Health Grants NS35255 (S.M.H., R.J.F.), NS37102 (R.J.F.), AG13846 (N.W.K., R.J.F.), AG12992 (M.F.B., N.W.K., R.J.F.), AT00613 (S.M.H., R.J.F., M.F.B.), NS 39258, NS 38180 (M.F.B.), and AG 14930 (T.M.J., A.J.L.C., M.F.B.), the Veterans Administration (R.J.F., N.W.K.), a Veterans Administration Research Enhancement Award Program grant (R.J.F.), and the Huntington's Disease Society of America. Expert assistance in histology preparation and animal husbandry was provided by Karen Smith and Kerry Courmier.

*M.F.B. and S.M.H. contributed equally to this work.

Correspondence should be addressed to Dr. Robert J. Ferrante, Geriatric Research Education and Clinical Center, Unit 182B, Bedford Veterans Affairs Medical Center, 200 Springs Road, Bedford, MA 01730. E-mail: rjferr@bu.edu.

Copyright (๑) 2002 Society for Neuroscience 0270-6474/02/228942-09\$15.00/0 esized that aggregation may be the trigger for a toxic gain of function, leading to neurodegeneration.

At least three transglutaminase (Tgase) isoenzymes are found in the brain (Tgase1, 2, and 3) of which Tgase 2 (tissue Tgase) is the most abundant (Kim et al., 1999). It has been suggested that Tgase may be involved in the etiology of HD by catalyzing the formation of $\gamma$-glutamyl isopeptide bonds between polyglutamine tracts and a lysine protein substrate, rendering the resulting cross-linked protein complexes insoluble (Folk, 1983; Green, 1993). $N^{\Sigma}$-( $\gamma$-L-glutamyl)-L-lysine (GGEL) is, therefore, a specific biomarker of Tgase activity. It is of interest that GGEL levels have been reported to be significantly elevated in the CSF of HD patients (Jeitner et al., 2001).

Tgase activity is upregulated in several other neuronal injury models and neurodegenerative diseases and may be a generalized response during neurodegeneration (Gilad et al., 1985; Holmes and Haynes, 1996; Fujita et al., 1998; Kim et al., 1999; Singer et al., 2002).

It has been shown in vitro that polyglutamine repeat domains and mutant htt are substrates for Tgase (Kahlem et al., 1996; Cariello et al., 1996; Cooper et al., 1997a,b; Kahlem et al., 1998). The substrate activity increases with increasing size of the polyglutamine domain (Karpuj et al., 1999; Gentile et al., 1998; de Cristofaro et al., 1999). Tgase activity is increased in postmortem HD brain in a grade-dependent manner (Karpuj et al., 1999; Lesort et al., 1999). The formation and maintenance of htt inclusions may therefore be the result, in part, of Tgase activity. Whereas Tgase 2 is predominantly a cytoplasmic protein, with 
increasing intracellular calcium levels, active Tgase 2 translocates to the nucleus and is placed in a position to contribute to the formation of nuclear inclusions (Karpuj et al., 1999; Lesort et al., 1999). Quantitative differences in brain Tgase activity and Tgase isoenzymes may possibly explain selective neuronal vulnerability in HD (Cooper et al., 2002).

We examined whether the administration of cystamine reduces Tgase activity and GGEL levels, lessens the behavioral and neuropathological severity, and extends survival in R6/2 transgenic HD mice.

These findings have been reported in preliminary form (Ferrante et al., 2001).

\section{MATERIALS AND METHODS}

Human tissue specimens. Postmortem tissue specimens of striatum and frontal cortex from 14 adult-onset HD patients (five grade 3, and nine grade 4 cases; mean age, 66.3 years; range, 53-74 years), and six agematched patients without any known neurological sequela (mean age, 68.1 years; range, 62-79) were dissected fresh and either placed in cold $\left(4^{\circ} \mathrm{C}\right) 2 \%$ paraformaldehyde-lysine-periodate solution for $24-36 \mathrm{hr}$ or flash frozen using liquid nitrogen vapors. Brain tissue specimens were received from the Bedford Veterans Affairs Medical Center Brain Tissue Archive, St. Louis Medical Center, and Emory University. The postmortem intervals did not exceed $18 \mathrm{hr}$ (mean time, $8.1 \mathrm{hr}$; range, 4-18 hr). The range of CAG repeats in the HD patients was 41-52. Each HD patient had been clinically diagnosed based on known family history and phenotypic symptoms of HD. The diagnosis of HD was confirmed by neuropathological examination and graded by our severity scale (Vonsattel et al., 1985). Tissue blocks were processed for histology, as previously described (Kuemmerle et al., 1999).

Animals. Male transgenic HD mice of the R6/2 strain were obtained from The Jackson Laboratory (Bar Harbor, ME). The male R6/2 mice were bred with females from their background strain (B6CBAFI/J). The offspring were genotyped using a PCR assay on tail DNA. The mice were housed four per cage under standard conditions with ad libitum access to water and food. To ensure homogeneity of the cohorts used in these experiments, we have standardized our criteria for placement of mice into testing groups. Mice were randomized from 38 litters all within $2 \mathrm{~d}$ of the same age from the same "f" generation. Any mice that had altered base-paired banding identified from PCR analysis were excluded from the study. All mice were weighed before placement and equally distributed according to weight within each cohort. Enrichment conditions were not applied to any cages because of its effect on improving phenotype in R6/2 mice. All mice were handled under the same conditions by one investigator. Equal numbers of mice from both genders were included in the experimental paradigm. We have not observed gender differences in survival in the R6/2 transgenic HD mouse model. All animal experiments were performed in accordance with the National Institutes of Health Guide for the Care and Use of Laboratory Animals and were approved by both the Veterans Administration and Boston University Animal Care Committees.

Intraperitoneal dosing. Based on the study of Boyko et al. (1998), we completed a dose-response study, treating wild-type (Wt) and R6/2 mice with 112,225 , and $400 \mathrm{mg} / \mathrm{kg}$ daily intraperitoneal injection of cystamine dihydrochloride (Sigma, St. Louis, MO) dissolved in PBS. Approximately 100 mice were used in the dosing study. At $21 \mathrm{~d}$ of age, groups of 20 R6/2 and littermate wild-type control mice were treated with 112 $\mathrm{mg} / \mathrm{kg}$ and $225 \mathrm{mg} / \mathrm{kg}$ cystamine, PBS, or untreated. In all, behavioral and survival data were obtained from $\sim 180$ R6/2 and littermate wildtype mice. During the temporal progress of the disease, the intraperitoneal injection was $100 \mu \mathrm{l} / 20 \mathrm{gm} / \mathrm{mouse}$ until endstage (17 weeks).

Oral dosing. Prenatal oral dosing at $225 \mathrm{mg} / \mathrm{kg}$ cystamine was initiated in breeding wild-type females and continued postnatally in the drinking water. Based on water consumption of $5 \mathrm{ml} / \mathrm{d}$ per $20 \mathrm{gm}$ mouse, a cystamine concentration of $900 \mathrm{mg} / 1$ tap water was used. Eight pregnant dams were used in the study, four cystamine-treated and four untreated under standard conditions with ad libitum access to water and food. Pups were genotyped at $15 \mathrm{~d}$, and mixed R6/2-positive and wild-type litters were kept together after weaning $(21 \mathrm{~d})$ in groups of four mice throughout the course of the survival experiment. Body weight and survival data were recorded for 30 cystamine-treated mice (16 R6/2-positive; 14 wildtype littermate mice) and 26 untreated mice (10 R6/2-positive; 16 wildtype littermate mice).
Motor performance and weight assessment. Motor performance was assessed weekly from 21-63 d of age and twice weekly from $63 \mathrm{~d}$ of age in the R6/2 mice. The mice were given two training sessions to acclimate them to the rotarod apparatus (Columbus Instruments, Columbus, $\mathrm{OH}$ ). Mice were placed on a rotating rod at $16 \mathrm{rpm}$. The length of time remaining on the rod was taken as the measure of competency. The maximum score was $60 \mathrm{sec}$, and each mouse performed three separate trials. The three results were averaged and recorded. Body weights were recorded twice weekly.

Survival. R6/2 mice were observed twice daily, mid-morning and late afternoon. Their motor performance and ability to feed was closely monitored and was the basis for determining when to euthanize the mice. The criteria for killing was the point in time in which the HD mice were unable to right themselves after being placed on their back and initiate movement after being gently prodded for $30 \mathrm{sec}$. HD mice have lost $\sim 40-50 \%$ of their body weight at this time point. Two independent observers confirmed the criteria for killing (R.J.F. and A.D.).

Transglutaminase and GGEL assays. At $21 \mathrm{~d}$ of age, groups of $10 \mathrm{R} 6 / 2$ and littermate wild-type control mice were treated with daily $112 \mathrm{mg} / \mathrm{kg}$ cystamine or PBS intraperitoneal injections. The mice were killed at $63 \mathrm{~d}$ of age, and the brains were rapidly frozen and stored at $-80^{\circ} \mathrm{C}$. Tgase activity was determined by a previously described method that measures tritiated putrescine in a protein substrate (Lesort et al., 1999). Putrescine incorporation was determined by liquid scintillation counts and calculated as picomoles per hour per milligram of tissue protein. Free GGEL levels were determined by liquid chromatography with electrochemical detection (LCEC). Brain samples were placed in cold $\left(4^{\circ} \mathrm{C}\right) 50 \%$ methanol $(100 \mathrm{mg} / 400 \mathrm{ml}$ methanol), sonicated for $3 \times 10 \mathrm{sec}$ cycles, protein levels were determined via Coomassie Protein Assay (Pierce, Rockford, IL), samples were centrifuged $\left(4^{\circ} \mathrm{C}, 40,000 \mathrm{rpm}\right.$ for $\left.1 \mathrm{hr}\right)$, and supernatant was extracted for GGEL assay. GGEL was analyzed using LCEC after $O$-phthaldialdehyde (OPA) $/ \beta$-mercaptoethanol derivatization, using a recently reported method (Jeitner et al., 2001) with the exception that an XTerra MS $5 \mu \mathrm{m}, 4.6 \mathrm{~mm} \times 25 \mathrm{~cm} \mathrm{C18}$ column (Waters, Milford, MA) was used for the separations. GGEL levels are reported as picomoles per microgram of tissue protein. Each of the sample measurements was performed twice, and identification was blinded to the investigators performing assays (J.K.K., S.M., M.B., and T.M.J.).

Histologic evaluation. At $21 \mathrm{~d}, \mathrm{R} 6 / 2$ transgenic mice and wild-type littermate control mice were treated with daily $112 \mathrm{mg} / \mathrm{kg}$ cystamine or PBS intraperitoneal injections. Groups of 10 animals from each treatment paradigm were deeply anesthetized and then transcardially perfused with $4 \%$ buffered paraformaldehyde at $90 \mathrm{~d}$ of age. Approximately 40 mice were used for data collection in the neuropathological analysis and processed for histopathology, as previously described (Ferrante et al., 2002). Serially cut tissue mouse and human tissue sections were stained for Nissl substance and immunostained for htt, using a polyclonal rabbit antibody (EM48; dilution, 1:1000; S. M. Hersch), two Tgase 2 antibodies (mouse monoclonal antibody, dilution, 1:200, NeoMarker Inc., Fremont, CA; goat polyclonal antibody, dilution, 1:400, Upstate Biotechnology, Lake Placid, NY), and an antibody to GGEL (anti-N epsilon gamma glutamyl lysine mouse monoclonal antibody, dilution, 1:500, Abcam Limited, Cambridge, UK), using a previously reported conjugated second antibody method in human and murine brain tissue samples (Ferrante et al., 2002). Specificity for the antisera used in this study was examined in each immunochemical experiment to assist with interpretation of the results. Preabsorption with excess target proteins, omission of the primary antibodies, and omission of secondary antibodies was performed to determine the amount of background generated from the detection assay.

Double immunofluorescence was performed using a previously described method (Ferrante et al., 1997) by incubating R6/2 mouse tissue sections in polyclonal rabbit htt antisera (EM48, dilution, 1:1000) and in either a monoclonal mouse Tgase antisera (NeoMarkers; dilution, 1:250) or in a mouse monoclonal GGEL antisera in Tris $\mathrm{HCl}$ buffer containing $0.3 \%$ Triton $\mathrm{X}-100$ for $24-72 \mathrm{hr}$ at $4^{\circ} \mathrm{C}$. htt antisera resulted in the presence of green fluorescence, whereas Tgase and GGEL antisera resulted in the presence of red fluorescence. Identical microscopic fields were photographed with a Nikon fluorescent microscope, delineating the location of htt and Tgase or GGEL immunoreactivities within the same brain tissue section and merged.

Stereology/quantitation. Serial cut coronal tissue-sections from the rostral segment of the neostriatum and neocortex at the level of the anterior commissure (interaural $5.34 \mathrm{~mm} /$ bregma $1.54 \mathrm{~mm}$ to interaural 3.7 $\mathrm{mm} /$ bregma $-0.10 \mathrm{~mm}$ ), were used for htt aggregate analysis. Unbiased 

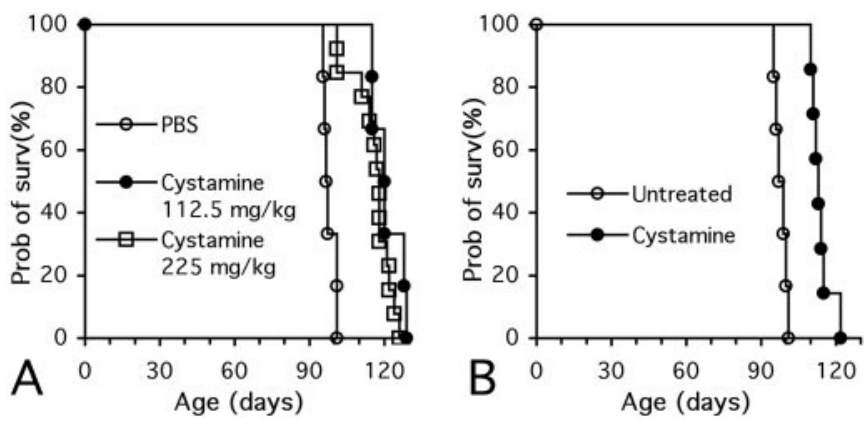

Figure 1. Survival in cystamine-treated R6/2 mice. Kaplan-Meier probability of survival analysis for cystamine treatment using intraperitoneal injection of 112 and $225 \mathrm{mg} / \mathrm{kg}$ in R6/2 mice and untreated R6/2 mice showing cumulative survival $(A)$. Survival analysis of oral treatment using $225 \mathrm{mg} / \mathrm{kg}(B)$. Both intraperitoneal and oral cystamine treatment significantly extended survival in $\mathrm{R} 6 / 2$ transgenic mice $(p<0.001)$.

stereologic counts of htt-positive aggregates $(\geq 1.0 \mu \mathrm{m})$ were obtained from the neostriatum in 10 mice each from cystamine-treated and PBStreated R6/2 mice at $90 \mathrm{~d}$ using Neurolucida Stereo Investigator software (Microbrightfield, Colchester, VT). The total areas of the neostriatum and neocortex were defined in serial sections in which counting frames were randomly sampled. The dissector counting method was used in which htt-positive aggregates were counted in an unbiased selection of serial sections in a defined volume of the neostriatum and neocortex. Striatal neuron areas were analyzed by microscopic videocapture using a Windows-based image analysis system for area measurement (Optimas; Bioscan Incorporated, Edmonds, WA). The software automatically identifies and measures profiles. All computer-identified cell profiles were manually verified as neurons and exported to Microsoft Excel. Crosssectional areas were analyzed using Statview.

Statistics. The data are expressed as the mean \pm SEM. Statistical comparisons of rotarod, weight data, and histology data were compared by ANOVA or repeated measures ANOVA. Survival data were analyzed by the Kaplan-Meier survival curves.

\section{RESULTS}

The effects of intraperitoneal injection and oral administration of cystamine on survival in HD R6/2 transgenic mice are shown in Figure 1. Intraperitoneal administration of cystamine significantly extended survival in R6/2 mice at both the $112 \mathrm{mg} / \mathrm{kg}$ and $225 \mathrm{mg} / \mathrm{kg}$ doses (PBS-treated R6/2 mice: $101.1 \pm 3.6 \mathrm{~d} ; 112$ $\mathrm{mg} / \mathrm{kg}$ cystamine-treated R6/2 mice: $120.8 \pm 5.8 \mathrm{~d}, p<0.001$; and $225 \mathrm{mg} / \mathrm{kg}$ cystamine-treated R6/2 mice: $118.3 \pm 4.3 \mathrm{~d}, p<0.001)$ (Fig. 1). All mice at a $400 \mathrm{mg} / \mathrm{kg}$ dosing regimen died within 2-5 $\mathrm{d}$ after treatment was initiated at $21 \mathrm{~d}$. At $\sim 83 \mathrm{~d}$ survival, during each of the two $225 \mathrm{mg} / \mathrm{kg}$ cystamine experiments, the treated mice became moribund, and treatment was stopped. Cystamine toxicity was suspected. Cystamine treatment was started again after a $7 \mathrm{~d}$ drug holiday at $90 \mathrm{~d}$. Although greater survival was observed using the $112 \mathrm{mg} / \mathrm{kg}$ dose, it was not significantly different from the $225 \mathrm{mg} / \mathrm{kg}$ dose. The percentage increase in survival for $112 \mathrm{mg} / \mathrm{kg}$ and $225 \mathrm{mg} / \mathrm{kg}$ cystamine dosing paradigms were 19.5 and $17.0 \%$, respectively.

The effects of prenatal oral administration of cystamine in drinking water administered to pregnant dams significantly increased survival in R6/2 littered-mice, as compared with unsupplemented dams and R6/2 littered-mice (Fig. 1). Oral cystamine treatment was continued in the drinking water from those litters born to cystamine-treated dams. Oral cystamine-treatment (225 mg/kg) significantly extended survival in R6/2 mice by $16.8 \%$ (unsupplemented R6/2 mice: $98.2 \pm 2.3 \mathrm{~d}$; cystaminetreated R6/2 mice: $114.1 \pm 5.5 \mathrm{~d}, p<0.01)$. No significant differences in survival were observed between the oral postnatal
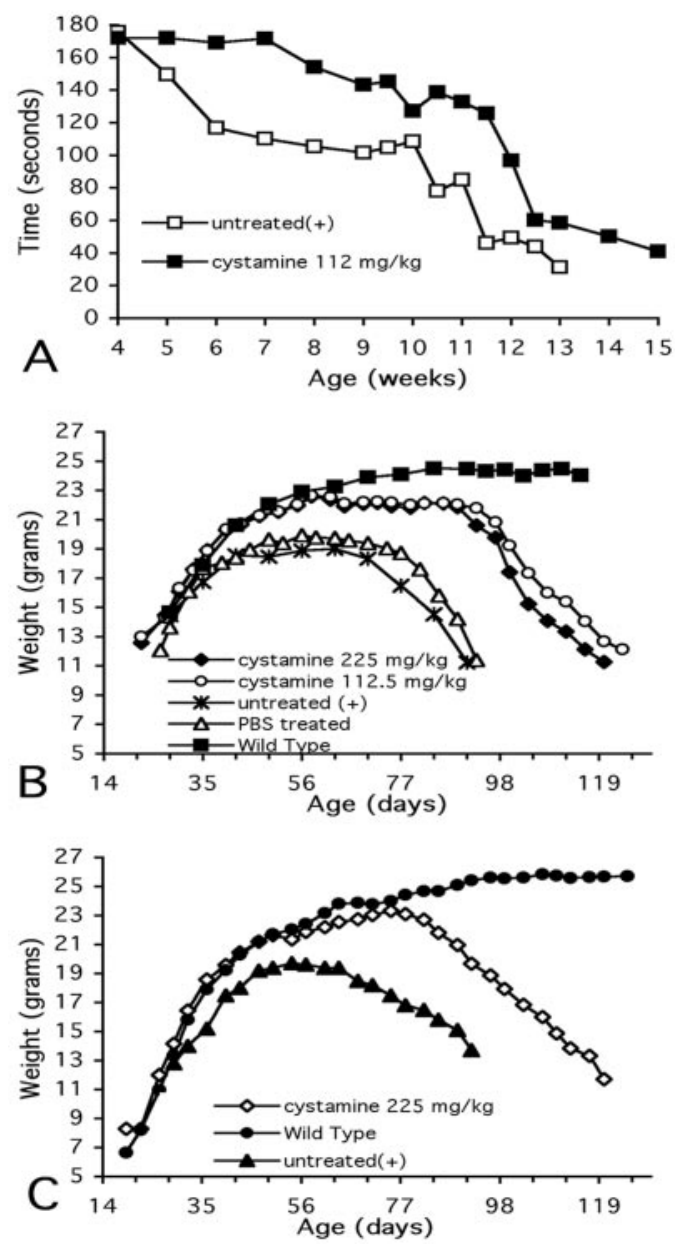

Figure 2. Motor performance and body weight analysis in cystaminetreated R6/2 mice. Effects of intraperitoneal cystamine treatment (112 $\mathrm{mg} / \mathrm{kg}$ ) on rotarod performance $(A)$ significantly improved motor performance in R6/2 HD transgenic mice throughout the temporal sequence of the experiment (4-16 weeks). Effects of intraperitoneal (112 and 225 $\mathrm{mg} / \mathrm{kg})(B)$ and oral $(225 \mathrm{mg} / \mathrm{kg})(C)$ cystamine treatment on body weight in R6/2 HD transgenic mice. Greater body weight improvement was observed in both the intraperitoneal and oral paradigms.

treatment and the intraperitoneal postweaning treatment using cystamine at $225 \mathrm{mg} / \mathrm{kg}$ in both experiments.

Intraperitoneal cystamine treatment $(112 \mathrm{mg} / \mathrm{kg})$ significantly improved rotarod performance throughout the entire measured (4-15 weeks) life span of the R6/2 mice in contrast to PBS-treated R6/2 mice (PBS-treated R6/2 mice: $79 \pm 26 \mathrm{sec} ; 112 \mathrm{mg} / \mathrm{kg}$ cystamine treated R6/2 mice: $137 \pm 17 \mathrm{sec}, p<0.01)$. The data represent combined means and SDs from 5 to 12.5 weeks (Fig. $2 A)$. The improvement in rotarod performance was $27 \%$.

The effects of $112 \mathrm{mg} / \mathrm{kg}$ and $225 \mathrm{mg} / \mathrm{kg}$ intraperitoneal cystamine treatment and prenatal oral treatment $(225 \mathrm{mg} / \mathrm{kg})$ on body weight in HD R6/2 transgenic mice are shown in Figure $2 B$. Each cystamine regimen resulted in significant improvement of body weight in comparison with unsupplemented R6/2 mice. Intraperitoneal cystamine treatment, 112 and $225 \mathrm{mg} / \mathrm{kg}$, resulted in significantly greater body weight gains in $\mathrm{R} 6 / 2$ mice $(p<0.01)$ in comparison with untreated R6/2 mice and untreated mice (Fig. $2 B)$. Significantly greater body weight measurements were present throughout the temporal sequence of measurements (4-17 weeks) in both 112 and $225 \mathrm{mg} / \mathrm{kg}$ cystamine-treated R6/2 
mice. At 9 and 12 week time points, the average differences between PBS-treated and both cystamine treatment paradigms were 15.2 and $48.9 \%$, respectively. The total gain in body weight from 4 to 17 weeks for both 112 and $225 \mathrm{mg} / \mathrm{kg}$ cystamine-treated R6/2 mice was 15.4 and $13.6 \%$ greater, respectively, in comparison with untreated R6/2 mice. Oral cystamine treatment (225 $\mathrm{mg} / \mathrm{kg}$ ) also resulted in significant body weight improvement across the life span of $\mathrm{R} 6 / 2$ mice $(p<0.01)$ (Fig. $2 C$ ). The total gain in body weight from 4 to 17 weeks for orally cystaminetreated R6/2 mice $(225 \mathrm{mg} / \mathrm{kg}$ ) was $12.7 \%$ greater, in comparison with unsupplemented R6/2 mice.

At $90 \mathrm{~d}$, there was a $21.1 \%$ reduction in brain weight in unsupplemented R6/2 mice, in contrast to littermate controls. In comparison, there was only a $5.7 \%$ brain weight loss in the 112 $\mathrm{mg} / \mathrm{kg}$ cystamine-treated R6/2 mice (Wt littermate mice: $461 \pm$ $12 \mathrm{mg} / \mathrm{kg}$; PBS-treated R6/2 mice: $364 \pm 17 ; 112 \mathrm{mg} / \mathrm{kg}$ cystamine-treated R6/2 mice: $435 \pm 10, p<0.01$ ). Concomitant with brain weight loss, marked gross atrophy with bilateral ventricular enlargement and flattening of the medial aspect of the striatum was present in the untreated R6/2 brains at $90 \mathrm{~d}$ (Fig. 3), as previously shown (Ferrante et al., 2000, 2002). Consistent with the brain weight findings, cystamine treatment reduced the gross brain atrophy in R6/2 mice in comparison with untreated mice (Fig. 3). In addition to the decrease in gross brain weight and brain atrophy, there was significant atrophy of striatal neurons at $90 \mathrm{~d}$ in R6/2 mice. Although neuronal size was smaller in the 112 $\mathrm{mg} / \mathrm{kg}$ cystamine-treated mice than in littermate control mice, the cytoprotective effect of $112 \mathrm{mg} / \mathrm{kg}$ cystamine treatment significantly delayed striatal neuron atrophy in comparison with unsupplemented R6/2 mice (Wt littermate control: $134 \pm 11 \mu \mathrm{m}^{2}$; unsupplemented R6/2: $57 \pm 15 \mu \mathrm{m}^{2}$; cystamine: $92 \pm 14 \mu \mathrm{m}^{2}$, $p<0.02$ ) (Fig. 3).

In the neostriatum and neocortex of R6/2 mice, there is an early and progressive accumulation of htt-positive aggregates, as well as an increase in aggregate size, from 21 to $90 \mathrm{~d}$ of age (Ferrante et al., 2000). Aggregates are much more prominent within the cortex in comparison with the neostriatum. Cystamine treatment of R6/2 mice resulted in a significant reduction in striatal and cortical aggregate number at $90 \mathrm{~d}$ of age $(p<0.01)$ (Fig. 4$)$, more so than in any other reported treatment paradigm to date. At $90 \mathrm{~d}$, the decreases in aggregate number in cystamine-treated R6/2 mice were 68 and $47 \%$ in the neostriatum and neocortex, respectively, as compared with untreated R6/2 mice (untreated R6/2 mice neocortex: $815 \times 10^{3}$; untreated $\mathrm{R} 6 / 2$ mice neostriatum: $520 \times 10^{3}$; cystamine-treated R6/2 mice neocortex: $424 \times 10^{3}$; cystamine-treated striatum: $166 \times 10^{3}$ ).

Brain Tgase activity was significantly elevated in R6/2 mice in comparison with wild-type littermate controls (Wt littermate mice: $0.65 \pm 0.10 \mathrm{pmol} \cdot \mathrm{hr}^{-1} \cdot \mathrm{mg}^{-1}$ protein; $\mathrm{R} 6 / 2$ mice: $0.87 \pm$ $0.11 \mathrm{pmol} \cdot \mathrm{hr}^{-1} \cdot \mathrm{mg}^{-1}$ protein, $p<0.01$ ) (Fig. $5 A$ ). In addition, daily intraperitoneal cystamine treatment in R6/2 mice significantly reduced levels of Tgase activity to the normal range found in littermate control mice (cystamine-treated R6/2 mice: $0.57 \pm$ $0.15 \mathrm{pmol} \cdot \mathrm{hr}^{-1} \cdot \mathrm{mg}^{-1}$ protein, $\left.p<0.01\right)$. There was no significant difference between cystamine-treated R6/2 mice and littermate control mice.

Whereas Tgase 2 immunoreactivity was present within both $\mathrm{R} 6 / 2$ and littermate control mouse brains (Fig. 5B,C), it was markedly greater in R6/2 tissue specimens at $90 \mathrm{~d}$. Tgase immunoreactivity was present in both the nucleus and cytoplasm of immunostained neurons, as well as in vascular elements. These findings are similar to those we observed in HD patients (Lesort
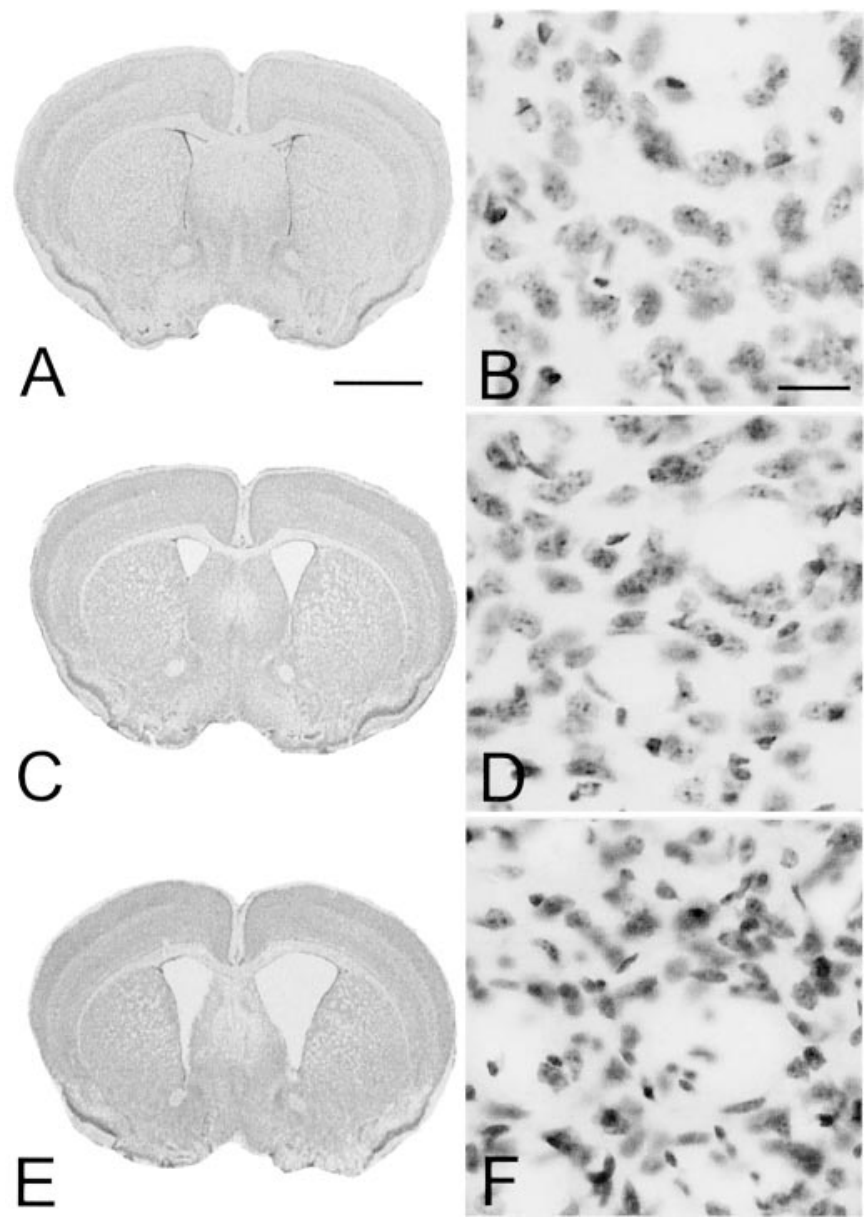

Figure 3. Gross brain and histopathological neuroprotection with cystamine treatment. Photomicrographs of coronal sections through the rostral neostriatum at the level of the anterior commissure in a wild-type littermate mouse $(A)$, cystamine-treated $(C)$, and untreated $(E)$ R6/2 HD transgenic mice at $90 \mathrm{~d}$. Note the generalized gross atrophy of the brain in the untreated R6/2 mouse along with enlargement of the lateral ventricles $(E)$. In contrast, the cystamine-treated $\mathrm{R} 6 / 2$ mouse at $90 \mathrm{~d}(C)$ shows significantly less atrophy and ventricular enlargement than the unsupplemented mouse. Corresponding Nissl-stained tissue sections from the dorsomedial aspect of the neostriatum $(B, D, F)$ with $A, C$, and $E$, respectively. Note the reduced neuronal size in the unsupplemented R6/2 mouse, with delayed neuronal atrophy in the cystamine-treated R6/2 mouse, in comparison with the control (A). Scale bars: (in $A) A, C, E$, $2 \mathrm{~mm}$; (in $B$ ) $B, D, F, 50 \mu \mathrm{m}$.

et al., 1999). Intensely immunostained Tgase 2-positive structures morphologically similar to mutant htt aggregates were found in R6/2 tissue specimens within neurons and the neuropil (Fig. 5C). Further characterization of these structures, using combined immunofluorescence for htt (FITC) and Tgase (TRITC) immunoreactivities, showed colocalization of htt aggregates and Tgase immunoreactivity (Fig. 5D-F). Approximately $10 \%$ of the mutant htt aggregates colocalized with Tgase-positive aggregates.

Free GGEL levels were significantly elevated in both the neocortex and caudate nucleus of severe to very severe grades in HD patients in comparison with non-neurologic age-matched control brain samples (HD neocortex: $525 \pm 104 \mathrm{pmol} / \mathrm{mg}$ protein; control neocortex: $69 \pm 13 \mathrm{pmol} / \mathrm{mg}$ protein, $p<0.001)(\mathrm{HD}$ caudate nucleus: $653 \pm 129 \mathrm{pmol} / \mathrm{mg}$ protein; control caudate nucleus: $62 \pm 12 \mathrm{pmol} / \mathrm{mg}$ protein, $p<0.001$ ) (Fig. $6 A$ ). In contrast, free GGEL levels in unsupplemented R6/2 mice were 

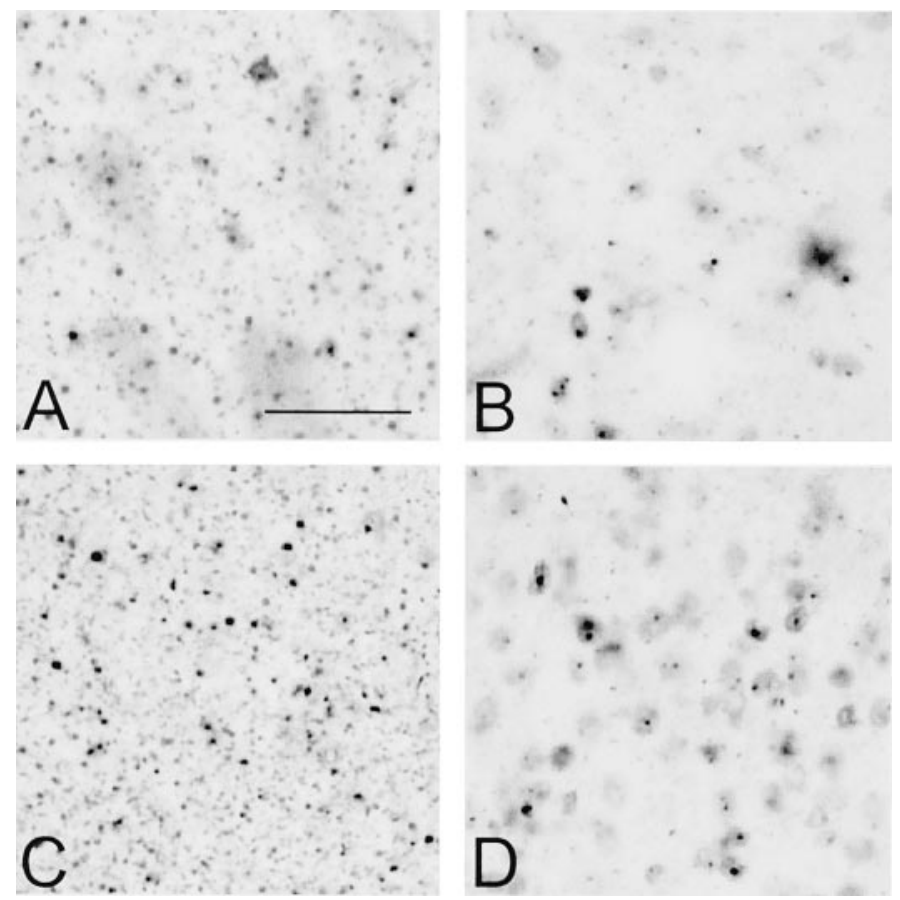

Figure 4. Huntingtin immunoreactivity in cystamine-treated R6/2 mice. htt-immunostained tissue sections from the neostriatum and layer six of the neocortex in untreated $(A, C$, respectively) and cystamine-treated $(B$, $D$, respectively) R6/2 HD transgenic mice at $90 \mathrm{~d}$. Although there is diff use immunoreactivity within nuclei in the cystamine-treated mice, the number and size of htt aggregates is significantly greater in the untreated R6/2 mice, in comparison with the cystamine-treated R6/2 mice. Diffuse nuclear immunostaining is present in the cystamine-treated mice. Scale bar, $100 \mu \mathrm{m}$.

significantly less in comparison with wild-type littermate controls (Wt littermate mice: $232 \pm 25 \mathrm{pmol} / \mathrm{mg}$ protein; $\mathrm{R} 6 / 2$ mice: $151 \pm$ $30 \mathrm{pmol} / \mathrm{mg}$ protein, $p<0.01$ ) (Fig. 6B). Intraperitoneal cystamine-treatment in R6/2 mice significantly increased GGEL levels, in comparison with untreated R6/2 mice (cystaminetreated R6/2 mice: $263 \pm 45 \mathrm{pmol} / \mathrm{mg}$ protein, $p<0.01)$, and is consistent with a beneficial therapeutic effect. There was no significant difference, however, in GGEL levels between cystamine-treated R6/2 mice and littermate controls. This finding in the mice may be related to the degree of sequestered GGEL in the insoluble mutant htt aggregate.

The GGEL immunocytochemical findings showed a marked increase in GGEL immunointensity in brain sections from both HD patients and R6/2 mice (Fig. 7). GGEL immunoreactivity was prominent in neurons and the vasculature. As with Tgase, there were GGEL-positive aggregates in R6/2 mice and HD patients (Fig. 7B,E). Both GGEL aggregates and immunoreactive intensity were reduced in the cystamine-treated R6/2 mice (Fig. $7 C$ ). Combined immunofluorescence for htt (FITC) and GGEL (TRITC) immunoreactivities showed colocalization of htt aggregates with GGEL immunoreactivity (Fig. 8A-C).

\section{DISCUSSION}

Although there have been enormous strides in the understanding of HD and the mutant gene, treatment to slow or prevent disease progression remains elusive. There has been, however, great excitement surrounding drug treatment in HD mice. The study of therapeutics in the transgenic mouse models has helped to develop a number of potential treatment strategies. Several pilot
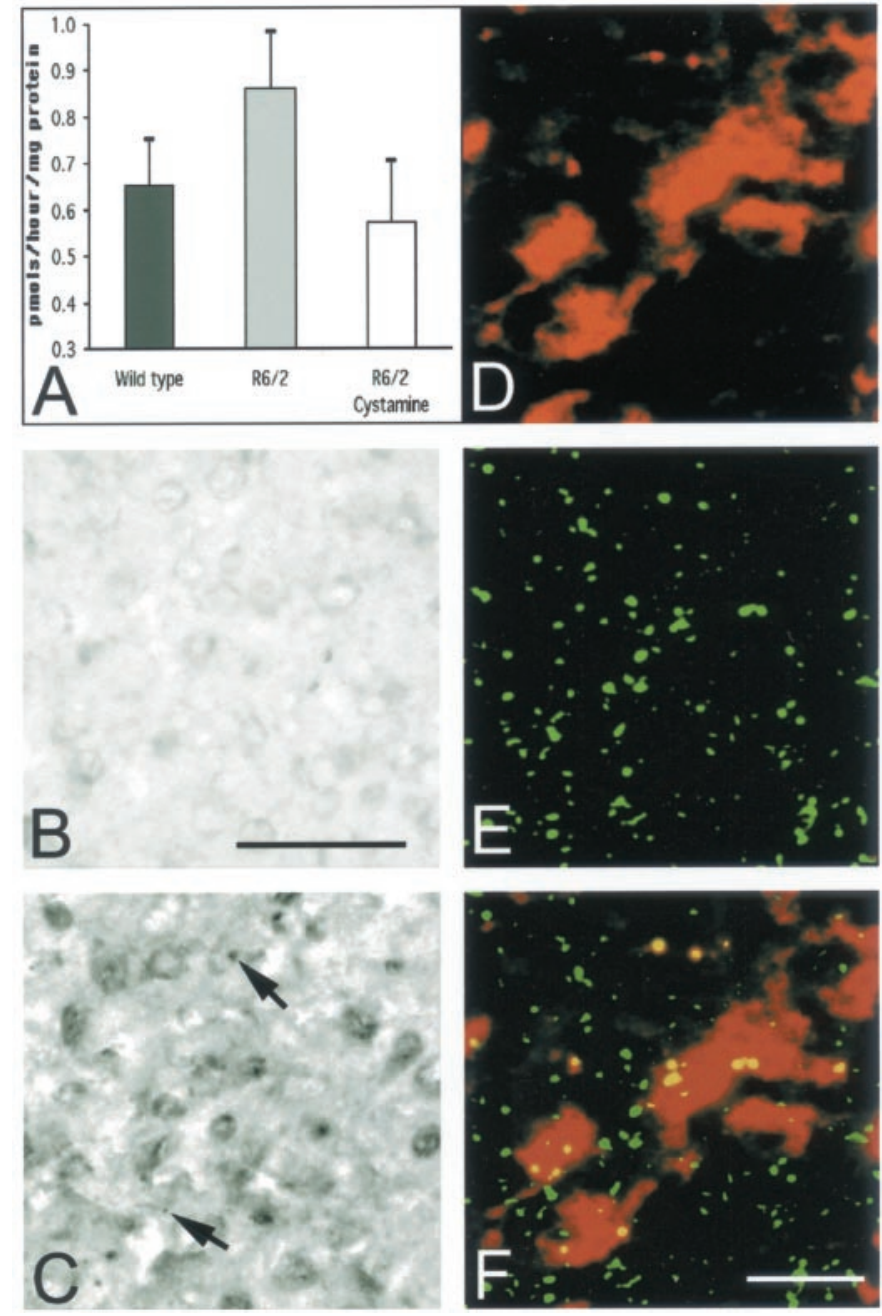

Figure 5. Transglutaminase activities in cystamine-treated R6/2 mice. Tgase activity is significantly increased in unsupplemented R6/2 mice in comparison with wild-type littermate control mice $(A)$. Cystamine treatment reduces Tgase activity to control levels $(A)$. Tgase immunoreactivity in a wild-type littermate mouse $(B)$ and an $\mathrm{R} 6 / 2$ mouse $(C)$ at $90 \mathrm{~d}$. There is light immunostaining in the wild-type control with increased immunoreactivity in the R6/2 mouse. Intense aggregate-like figures (arrows) are present in neurons and the neuropil of R6/2 mice $(C)$. Combined immunofluorescence within the same tissue section of an R6/2 mouse for Tgase $(r e d)(D)$ and huntingtin ( green) $(E)$ immunoreactivities show that there is partial colocalization between htt-positive aggregates and Tgasepositive aggregate figures (yellow) within the merged figures $(F)$. Scale bars: (in $B) B, C, 100 \mu \mathrm{m}$; (in $F$ ) $D, E, F, 20 \mu \mathrm{m}$.

clinical trials in HD patients have recently been initiated based on findings observed in mouse trials (remacemide, coenzyme Q10, minocycline, creatine) (Chen et al., 2000; Ferrante et al., 2000, 2002; Andreassen et al., 2001).

Green first hypothesized the involvement of Tgase in HD (Green, 1993). There are several strong lines of evidence in support of this hypothesis. Tgases are a family of calciumactivated enzymes, which catalyze the formation of $\gamma$-glutamyl isopeptide bonds between substrate proteins, often rendering the resulting cross-linked protein complexes insoluble. Expanded polyglutamine repeats are excellent glutamyl-donor substrates of tissue Tgase. Studies have shown that htt, and other polyglutamine-containing constructs, are in vitro substrates of Tgase and that Tgase may be involved in htt aggregation (Kahlem et al., 

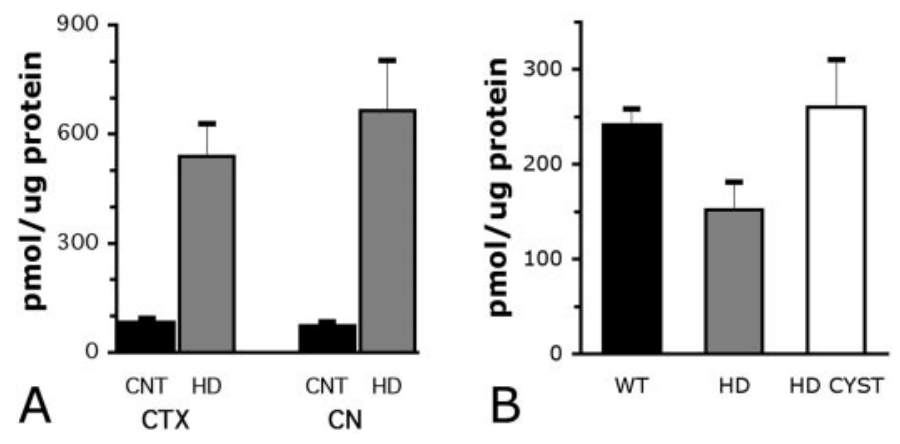

Figure 6. Brain GGEL levels in Huntington's disease patients and R6/2 mice. Free GGEL levels in both the neocortex and caudate nucleus in severe grades of $\mathrm{HD}$ were markedly elevated in HD patients as compared with non-neurologic control patients $(A)$. Free GGEL levels in unsupplemented R6/2 mice, however, were significantly reduced in comparison with WT littermate control mice, with improved GGEL levels in cystamine-treated R6/2 mice. htt aggregate formation is markedly greater in R6/2 mice than in HD patients. GGEL is colocalized with and sequestered in insoluble htt aggregates. This may result in artificially lowered free GGEL levels observed in R6/2 mice.

1996; Cooper et al., 1997, 2000, 2002; Karpuj et al., 2002b). We and others have reported that levels of Tgase are elevated in HD in a grade-of-severity-dependent manner (Karpuj et al., 1999; Lesort et al., 1999). It has been demonstrated in cell model systems that Tgase inhibitors suppress aggregate formation and reduce cell death (Igarashi et al., 1998; de Cristofaro et al., 1999; Oliverio et al., 1999). Tgase mediates htt aggregation in vitro and has a direct correlation to polyQ domain size (Karpuj et al., $2002 \mathrm{~b}$ ). In addition, it has been reported that induction of Tgase 2 gene expression, as a consequence of retinoic acid treatment, results in in vitro cell death (Oliverio et al., 1999). Together, these findings suggest that Tgase may play a role in aggregate formation and possibly neuronal cell death in polyglutamine repeat diseases.

Cystamine is the disulfide form of the free thiol, cysteamine. Both cystamine and cysteamine have been reported to inhibit Tgase (Lorand and Conrad, 1984; Uhl and Schindler, 1987; Cooper et al., 2002). Cystamine and monodansyl cadaverine, another Tgase inhibitor, can inhibit the formation of cellular aggregates produced by truncated dentatorubral-pallidoluysian atrophy proteins containing expanded polyglutamine stretches and partially suppress apoptotic cell death (Igarashi et al., 1998; Kahlem et al., 1998). The ratio of cellular glutathione to glutathione disulfide ensures that cystamine is significantly reduced to cysteamine (Cooper and Krystal, 1997). Cooper et al. (2002) suggest that cysteamine is the likely inhibitor of Tgase. The extent of the roles both cystamine and cysteamine play in the observed effects are under further investigation.

In the present experiments, we show that both oral and intraperitoneal cystamine treatment significantly extends survival in the R6/2 model of HD by 16.8 and $19.5 \%$, respectively. In addition, cystamine treatment significantly improved motor performance; delayed loss of body weight, gross brain weight and atrophy, and striatal neuron atrophy; and greatly attenuated the development of mutant-htt aggregates. Levels of Tgase activity and Tgase 2 immunoreactivity were greater in R6/2 mice than in littermate control mice and were reduced by cystamine treatment. Tgase immunoreactivity colocalized to mutant htt aggregates. Cystamine treatment significantly increased free GGEL in the R6/2 mice, consistent with a therapeutic effect. Protein-bound GGEL immunoreactivity determined histologically was markedly

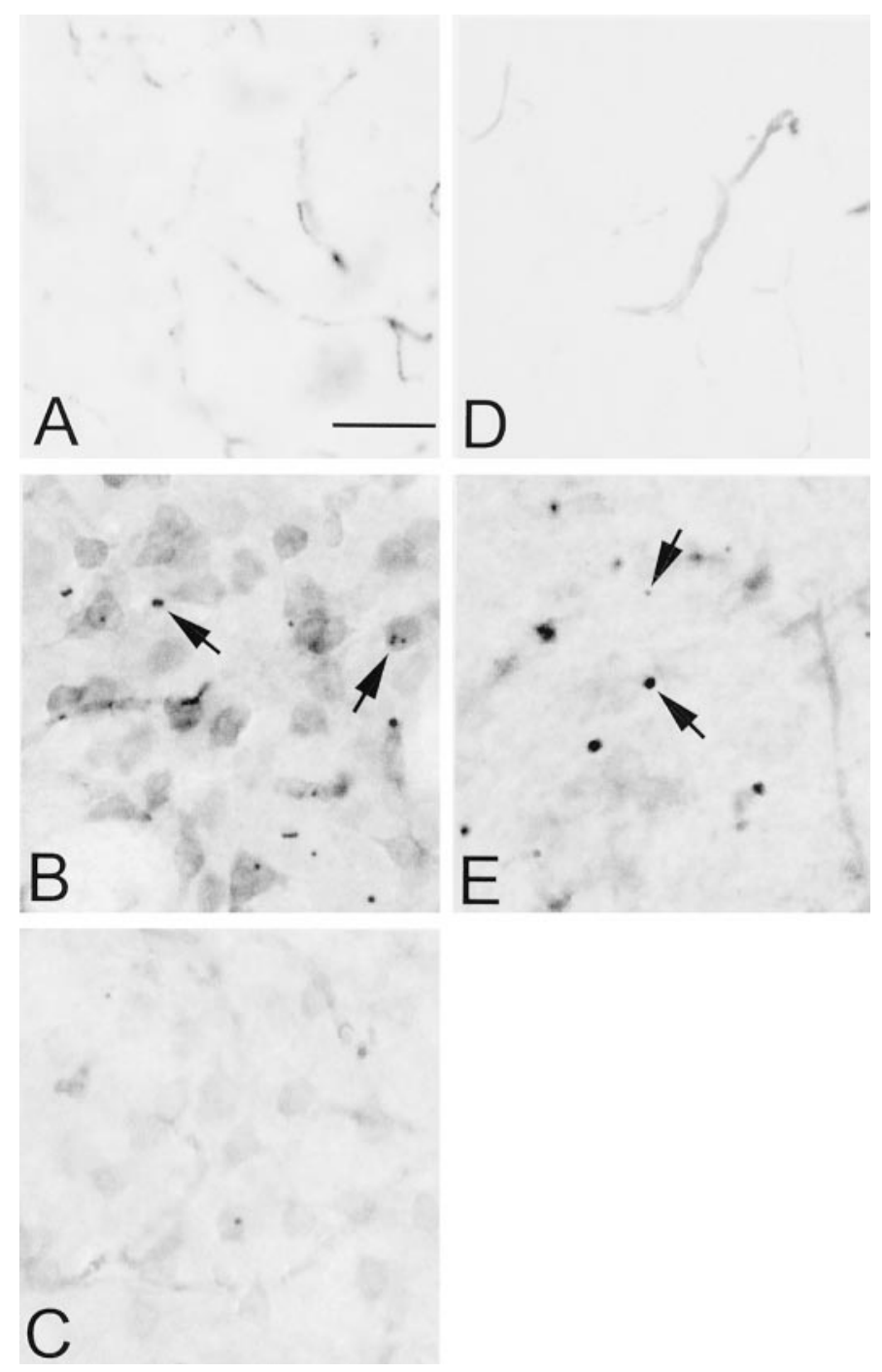

Figure 7. Protein-bound GGEL immunoreactivity in R6/2 mice and HD patients. GGEL immunocytochemical findings in $\mathrm{R} 6 / 2$ mice $(A-C)$ show a marked increase in GGEL immunointensity in brain sections from R6/2 mice at $90 \mathrm{~d}(B)$, in comparison with wild-type littermate control mouse $(A)$. GGEL immunoreactivity was found in neurons and the vasculature in R6/2 mice, with intensely immunostained aggregate-like structures in both neurons and the neuropil (arrows). In contrast, cystamine-treated R6/2 mice show reduced GGEL immunoreactivity and fewer aggregates $(C)$, consistent with reduced htt aggregates in treated $\mathrm{R} 6 / 2$ mice seen in Figure 4. The neocortex (lamina 6) from a grade $3 \mathrm{HD}$ patient shows a similar increase in GGEL immunoreactivity $(E)$, in comparison with an age-matched control $(D)$. GGEL-positive aggregates are present in the HD neocortex (arrows). Scale bar, $50 \mu \mathrm{m}$.

increased in both HD patients and R6/2 mice and colocalized with mutant htt aggregates. These findings demonstrate that cystamine has significant efficacy in improving the neurological and neuropathological phenotype observed in the R6/2 transgenic model of HD and strongly suggests that Tgase plays a role in HD.

Tgase catalyzes the formation of covalent linkages between a glutamine protein residue and lysine protein residue, forming a GGEL linkage. GGEL, therefore, is a specific biochemical marker of Tgase activity. We show that free GGEL levels were significantly elevated in both cortex and caudate nucleus of HD patients. In support of our findings, it has recently been shown that free GGEL is significantly increased in the CSF of HD 


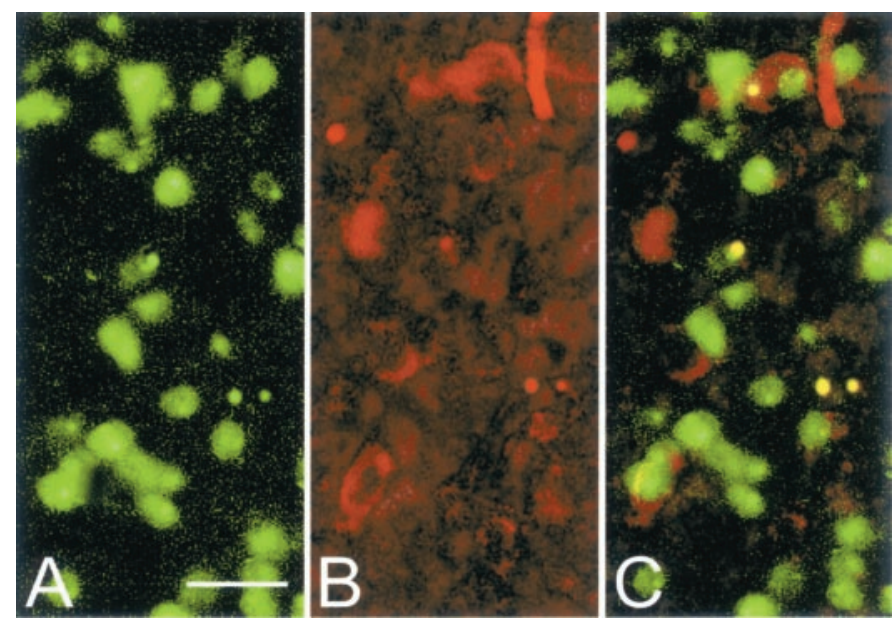

Figure 8. Combined GGEL and mutant htt immunofluorescence in R6/2 mice and HD patients. Combined immunofluorescence for htt (green) $(A)$ and GGEL (red) $(B)$ immunoreactivities within the same tissue specimens from the neostriatum of a 90 -d-old R6/2 mouse show colocalization of htt aggregates and GGEL immunostaining in the merged figure (yellow) $(C)$. Scale bar, $100 \mu \mathrm{m}$.

patients (Jeitner et al.,2001). Although protein-bound GGEL histologic immunoreactivity was markedly increased in R6/2 mice, free GGEL levels measured biochemically were reduced in unsupplemented R6/2 mice, in comparison with both wild-type and cystamine-treated R6/2 mice. This finding in the mice may be related to the degree of sequestered GGEL in the insoluble mutant htt aggregate. There are markedly greater numbers of htt aggregates within the R6/2 mouse model of HD than in patients with HD. It is possible that the difference may be the result of a decrease in free GGEL formation (from the proteolysis of crosslinked proteins) caused by sequestration in insoluble deposits and/or to increased degradation of free GGEL by $\gamma$-glutamylamine cyclotransferase and membrane-bound $\gamma$-glutamylamine transpeptidase (Danson et al., 2002).

Karpuj et al. (2002a) have recently reported that cystamine treatment initiated at 7 weeks, after clinical signs have appeared, prolonged survival by $\sim 12 \%$ in R6/2 HD mice. This was much less than the present findings and may reflect delayed treatment after symptoms were present or dosing differences. In addition, although there was a delay in both weight loss and limb clasping, neuropathological analysis did not show any amelioration of htt aggregates between cystamine-treated and PBS-untreated R6/2 mice. In contrast, we found a marked reduction in htt aggregates in R6/2 mice in which cystamine treatment was initiated at an earlier time point. It is possible that Tgase may be involved with the cross-linking of htt in smaller fragments (microaggregates), resulting in the nidus for disease. This is consistent with other findings that macroscopic aggregates do not correlate with cell death (Saudou et al., 1998; Klement et al., 1998; Kuemmerle et al., 1999). Collectively, our findings suggest that cystamine can inhibit aggregate formation and may be most beneficial as a treatment given before the onset of clinical phenotype.

Three theories, which are not mutually exclusive, have been proposed concerning the potential mechanism of htt aggregation in HD. Perutz et al. (1994) has suggested that expanded CAG repeats interact to form a polar zipper. Polymerization of htt and aggregate formation occurs in vitro only when the polyglutamine repeat is above 36 (Scherzinger et al., 1997). The second hypothesis, proposed by Green (1993) and Kahlem et al. (1996) suggests that Tgases may cross-link polyglutamine tracts into htt aggregates in HD. Aggregates can occur in the absence of Tgase, as shown in vitro in cell-free systems (Scherzinger et al., 1997). However, it is possible that initial polymerization could occur by a polar zipper mechanism followed by covalent cross-linking by Tgase. Finally, a toxic-channel hypothesis has been suggested in which long-chain polyglutamines form relatively stable microhelical channels that remain in an open state (Monoi et al., 2000). These channels are permeable to monovalent cations and dissipate electrochemical proton and voltage gradients across membranes, reducing ATP production.

The exact mechanism or mechanisms by which cystamine treatment is beneficial to R6/2 mice is unclear and may be multifold. Cystamine has a therapeutic role in a number of clinical conditions (McDonnell et al., 1997; Boyko et al., 1998; Iwata et al., 1998; Misik et al., 1999; Qiu et al., 2000). In addition to modulating Tgase activity and subsequent protein aggregation, cystamine may act as an antioxidant. Oxidative stress may play a role in both HD mice and patients (Browne et al., 1999; Bogdanov et al., 2001). We found that application of cystamine in an in vitro model of oxidative stress is cytoprotective and increases glutathione levels (R. R. Ratan, unpublished data). Glutathione is a principle substrate for the detoxification of reactive oxygen species. Maintenance of high glutathione levels may be an important mechanism by which cystamine treatment improves the behavioral and neuropathological phenotype in the R6/2 transgenic mouse model of HD. Cystamine has also been suggested to ameliorate apoptosis (Igarashi et al., 1998; Oliverio et al., 1999). The potential for cystamine to play a neuroprotective role via glutathione replenishment and/or caspase inhibition, therefore, needs further investigation.

Although the cause of neuronal death in HD remains unknown, specific early molecular events may lead to a progressive cascade of generic pathogenic processes. It has been widely postulated that the mutant htt protein may cause toxic effects in neurons, leading to a cascade of pathogenic mechanisms, including oxidative stress, mitochondrial dysfunction, energy metabolism defects, apoptosis, and excitotoxicity. An important event in this cascade may be transcriptional dysregulation through direct binding of the mutant htt protein to transcription factors, disrupting the normal pattern of gene transcription and altering gene expression in those pathogenic mechanisms associated with HD (Cha et al., 2000; Lin et al., 2000; Steffan et al., 2000). It is possible that cystamine may act by increasing transcription of neuroprotective factors in HD (Karpuj et al., 2002a). Alternatively, cystamine attenuates the development of huntingtin inclusions and, therefore, may act in part by reducing transcription factor sequestration, which is known to occur within insoluble htt aggregates (Cha, 2000; Steffan et al., 2000).

The prospects for neuroprotective treatment in HD patients are rapidly brightening. Our findings underscore the importance of the power of transgenic mouse models of HD for the screening of novel therapeutics. The positive effects of cystamine in R6/2 transgenic mice provide further evidence that Tgase may contribute to HD pathogenesis, although it is unclear what role other mechanisms of action of cystamine may play in improving both the behavioral and neuropathological phenotype. Regardless, these studies have identified a novel therapeutic strategy that may be successfully translated to human clinical trials and the subsequent treatment of HD patients. 


\section{REFERENCES}

Andreassen OA, Ferrante RJ, Huang HM, Dedeoglu A, Park L, Ferrante KL, Kwon J, Borchelt DR, Ross CA, Gibson GE, Beal MF (2001) Dichloroacetate exerts therapeutic effects in transgenic mouse models of Huntington's disease. Ann Neurol 50:112-117.

Bogdanov MB, Andreassen OA, Dedeoglu A, Ferrante RJ, Beal MF (2001) Increased oxidative damage to DNA in a transgenic mouse model of Huntington's disease. J Neurochem 79:1246-1249.

Boyko VN, Zholus RB, Legeza VI (1998) A study of the influence of different types of radioprotectors on the survival of mice treated with ionizing radiation over a wide dose range. Drugs Exp Clin Res 24:343-347.

Browne SE, Ferrante RJ, Beal MF (1999) Oxidative stress in Huntington's disease. Brain Pathol 9:147-163.

Cariello L, de Cristofaro T, Zanetti L, Cuomo T, Di Maio L, Campanella G, Rinaldi S, Zanetti P, Di Lauro R, Varrone S (1996) Transglutaminase activity is related to CAG repeat length in patients with Huntington's disease. Hum Genet 98:633-635.

Cha JH (2000) Transcriptional dysregulation in Huntington's disease. Trends Neurosci 23:387-392.

Chen M, Ona VO, Li M, Ferrante RJ, Fink KB, Zhu S, Bian J, Guo L, Farrell LA, Hersch SM, Hobbs W, Vonsattel JP, Cha JH, Friedlander RM (2000) Minocycline inhibits caspase-1 and caspase-3 expression and delays mortality in a transgenic mouse model of Huntington disease. Nat Med 6:797-801.

Cooper AJ, Sheu KF, Burke JR, Onodera O, Strittmatter WJ, Roses AD, Blass JP (1997a) Polyglutamine domains are substrates of tissue transglutaminase: does transglutaminase play a role in expanded $\mathrm{CAG} /$ poly-Q neurodegenerative diseases? J Neurochem 69:431-434.

Cooper AJ, Sheu KR, Burke JR, Onodera O, Strittmatter WJ, Roses AD, Blass JP (1997b) Transglutaminase-catalyzed inactivation of glyceraldehyde 3-phosphate dehydrogenase and alpha-ketoglutarate dehydrogenase complex by polyglutamine domains of pathological length. Proc Natl Acad Sci USA 94:12604-12609.

Cooper AJ, Wang J, Pasternack R, Fuchsbauer HL, Sheu RK, Blass JP (2000) Lysine-rich histone (H1) is a lysyl substrate of tissue transglutaminase: possible involvement of transglutaminase in the formation of nuclear aggregates in $(\mathrm{CAG})(\mathrm{n}) / \mathrm{Q}(\mathrm{n})$ expansion diseases. Dev Neurosci 22:404-417.

Cooper AJ, Jeitner TM, Gentile V, Blass JP (2002) Cross linking of polyglutamine domains catalyzed by tissue transglutaminase is greatly favored with pathological-length repeats: does transglutaminase activity play a role in $(\mathrm{CAG})(\mathrm{n}) / \mathrm{Q}(\mathrm{n})$-expansion diseases? Neurochem Int 40:53-67.

Cooper AJL, Krystal BS (1997) Multiple roles of glutathione in the central nervous system. Biol Chem 378:793-802.

Danson JW, Trawick ML, Cooper AJ (2002) Spectrophotometric assays for L-lysine alpha-oxidase and gamma-glutamylamine cyclotransferase. Anal Biochem 303:120-130.

Davies SW, Turmaine M, Cozens BA, DiFiglia M, Sharp AH, Ross CA, Scherzinger E, Wanker EE, Mangiarini L, Bates GP (1997) Formation of neuronal intranuclear inclusions underlies the neurological dysfunction in mice transgenic for the HD mutation. Cell 90:537-548.

de Cristofaro T, Affaitati A, Cariello L, Avvedimento EV, Varrone S (1999) The length of polyglutamine tract, its level of expression, the rate of degradation, and the transglutaminase activity influence the formation of intracellular aggregates. Biochem Biophys Res Commun 260:150-158.

DiFiglia M, Sapp E, Chase KO, Davies SW, Bates GP, Vonsattel JP, Aronin N (1997) Aggregation of huntingtin in neuronal intranuclear inclusions and dystrophic neurites in brain. Science 277:1990-1993.

Ferrante RJ, Gutekunst CA, Persichetti F, McNeil SM, Kowall NW, Gusella JF, MacDonald ME, Beal MF, Hersch SM (1997) Heterogeneous topographic and cellular distribution of huntingtin expression in the normal human neostriatum. J Neurosci 17:3052-3063.

Ferrante RJ, Andreassen OA, Jenkins BG, Dedeoglu A, Kuemmerle S, Kubilus JK, Kaddurah-Daouk R, Hersch SM, Beal MF (2000) Neuroprotective effects of creatine in a transgenic mouse model of Huntington's disease. J Neurosci 20:4389-4397.

Ferrante RJ, Dedeoglu A, Mahoney S, Beal MF, Hersch SM (2001) Neuroprotective effects of cystamine in Huntington's disease transgene R6/2 mice. Soc Neurosci Abstr 27:578.9.

Ferrante RJ, Andreassen OA, Dedeoglu A, Ferrante KL, Jenkins BG, Hersch SM, Beal MF (2002) Therapeutic effects of coenzyme Q10 and remacemide in transgenic mouse models of Huntington's disease. J Neurosci 22:1592-1599.

Folk JE (1983) Mechanism and basis for specificity of transglutaminasecatalyzed epsilon-(gamma-glutamyl) lysine bond formation. Adv Enzymol Relat Areas Mol Biol 54:1-56.

Fujita K, Honda M, Hayashi R, Ogawa K, Ando M, Yamauchi M, Nagata Y (1998) Transglutaminase activity in serum and cerebrospinal fluid in sporadic amyotrophic lateral sclerosis: a possible use as an indicator of extent of the motor neuron loss. J Neurol Sci 158:53-57.

Gentile V, Sepe C, Calvani M, Melone MA, Cotrufo R, Cooper AJ, Blass
JP, Peluso G (1998) Tissue transglutaminase-catalyzed formation of high-molecular-weight aggregates in vitro is favored with long polyglutamine domains: a possible mechanism contributing to CAG-triplet diseases. Arch Biochem Biophys 352:314-321.

Gilad GM, Varon LE, Gilad VH (1985) Calcium-dependent transglutaminase of rat sympathetic ganglion in development and after nerve injury. J Neurochem 44:1385-1390.

Goldberg YP, Nicholson DW, Rasper DM, Kalchman MA, Koide HB, Graham RK, Bromm M, Kazemi-Esfarjani P, Thornberry NA, Vaillancourt JP, Hayden MR (1996) Cleavage of huntingtin by apopain, a proapoptotic cysteine protease, is modulated by the polyglutamine tract. Nat Genet 13:442-449.

Green H (1993) Human genetic diseases due to codon reiteration: relationship to an evolutionary mechanism. Cell 74:955-956.

Holmes FE, Haynes LW (1996) Superactivation of transglutaminase type 2 without change in enzyme level occurs during progressive neurodegeneration in the mnd mouse mutant. Neurosci Lett 213:185-188.

Huntington's Disease Collaborative Research Group (1993) A novel gene containing a trinucleotide repeat that is expanded and unstable on Huntington's disease chromosomes. Cell 72:971-983.

Igarashi S, Koide R, Shimohata T, Yamada M, Hayashi Y, Takano H, Date H, Oyake M, Sato T, Sato A, Egawa S, Ikeuchi T, Tanaka H, Nakano R, Tanaka K, Hozumi I, Inuzuka T, Takahashi H, Tsuji S (1998) Suppression of aggregate formation and apoptosis by transglutaminase inhibitors in cells expressing truncated DRPLA protein with an expanded polyglutamine stretch. Nat Genet 18:111-117.

Iwata F, Kuehl EM, Reed GF, McCain LM, Gahl WA, Kaiser-Kupfer MI (1998) A randomized clinical trial of topical cysteamine disulfide (cystamine) versus free thiol (cysteamine) in the treatment of corneal cystine crystals in cystinosis. Mol Genet Metab 64:237-242.

Jeitner TM, Bogdanov MB, Matson WR, Daikhin Y, Yudkoff M, Folk JE, Steinman L, Browne SE, Beal MF, Blass JP, Cooper AJ (2001) $N($ epsilon)-(gamma-L-glutamyl)-L-lysine (GGEL) is increased in cerebrospinal fluid of patients with Huntington's disease. J Neurochem 79:1109-1112.

Kahlem P, Terre C, Green H, Djian P (1996) Peptides containing glutamine repeats as substrates for transglutaminase-catalyzed cross-linking: relevance to diseases of the nervous system. Proc Natl Acad Sci USA 93:14580-14585.

Kahlem P, Green H, Djian P (1998) Transglutaminase action imitates Huntington's disease: selective polymerization of Huntingtin containing expanded polyglutamine. Mol Cell 1:595-601.

Karpuj MV, Garren H, Slunt H, Price DL, Gusella J, Becher MW, Steinman L (1999) Transglutaminase aggregates huntingtin into nonamyloidogenic polymers, and its enzymatic activity increases in Huntington's disease brain nuclei. Proc Natl Acad Sci USA 96:7388-7393

Karpuj MV, Becher MW, Springer JE, Chabas D, Youssef S, Pedotti R, Mitchell D, Steinman L (2002a) Prolonged survival and decreased abnormal movements in transgenic model of Huntington disease, with administration of the transglutaminase inhibitor cystamine. Nat Med 8:143-149.

Karpuj MV, Becher MW, Steinman L (2002b) Evidence for a role for transglutaminase in Huntington's disease and the potential therapeutic implications. Neurochem Int 40:31-36.

Kim SY, Grant P, Lee JH, Pant HC, Steinert PM (1999) Differential expression of multiple transglutaminases in human brain. Increased expression and cross-linking by transglutaminases 1 and 2 in Alzheimer's disease. J Biol Chem 274:30715-30721.

Klement IA, Skinner PJ, Kaytor MD, Yi H, Hersch SM, Clark HB, Zoghbi HY, Orr HT (1998) Ataxin-1 nuclear localization and aggregation: role in polyglutamine-induced disease in SCA1 transgenic mice. Cell 95:41-53.

Kuemmerle S, Gutekunst CA, Klein AM, Li XJ, Li SH, Beal MF, Hersch SM, Ferrante RJ (1999) Huntington aggregates may not predict neuronal death in Huntington's disease. Ann Neurol 46:842-849.

Lesort M, Chun W, Johnson GV, Ferrante RJ (1999) Tissue transglutaminase is increased in Huntington's disease brain. J Neurochem 73:2018-2027.

Li SH, Li XJ (1998) Aggregation of N-terminal huntingtin is dependent on the length of its glutamine repeats. Hum Mol Genet 7:777-782.

Lin X, Antalffy B, Kang D, Orr HT, Zoghbi HY (2000) Polyglutamine expansion down-regulates specific neuronal genes before pathologic changes in SCA1. Nat Neurosci 3:157-163.

Lorand L, Conrad SM (1984) Transglutaminases. Mol Cell Biochem $58: 9-35$.

Martindale D, Hackam A, Wieczorek A, Ellerby L, Wellington C, McCutcheon K, Singaraja R, Kazemi-Esfarjani P, Devon R, Kim SU, Bredesen DE, Tufaro F, Hayden MR (1998) Length of huntingtin and its polyglutamine tract influences localization and frequency of intracellular aggregates. Nat Genet 18:150-154.

McDonnell NB, De Guzman RN, Rice WG, Turpin JA, Summers MF (1997) Zinc ejection as a new rationale for the use of cystamine and 
related disulfide-containing antiviral agents in the treatment of AIDS. J Med Chem 40:1969-1976.

Misik V, Miyoshi N, Riesz P (1999) Effects of cysteamine and cystamine on the sonochemical accumulation of hydrogen peroxide-implications for their mechanisms of action in ultrasound-exposed cells. Free Radic Biol Med 26:961-967.

Monoi H, Futaki S, Kugimiya S, Minakata H, Yoshihara K (2000) PolyL-glutamine forms cation channels: relevance to the pathogenesis of the polyglutamine diseases. Biophys J 78:2892-2899.

Oliverio S, Amendola A, Rodolfo C, Spinedi A, Piacentini M (1999) Inhibition of tissue transglutaminase increases cell survival by preventing apoptosis. J Biol Chem 274:34123-34128.

Perutz MF, Johnson T, Suzuki M, Finch JT (1994) Glutamine repeats as polar zippers: their possible role in inherited neurodegenerative diseases. Proc Natl Acad Sci USA 91:5355-5358.

Qiu L, Zhang M, Sturm RA, Gardiner B, Tonks I, Kay G, Parsons PG (2000) Inhibition of melanin synthesis by cystamine in human melanoma cells. J Invest Dermatol 114:21-27.

Saudou F, Finkbeiner S, Devys D, Greenberg ME (1998) Huntingtin acts in the nucleus to induce apoptosis but death does not correlate with the formation of intranuclear inclusions. Cell 95:55-66.

Scherzinger E, Lurz R, Turmaine M, Mangiarini L, Hollenbach B, Hasenbank R, Bates GP, Davies SW, Lehrach H, Wanker EE (1997) Huntingtin-encoded polyglutamine expansions form amyloid-like protein aggregates in vitro and in vivo. Cell 90:549-558.

Singer SM, Zainelli GM, Norlund MA, Lee JM, Muma NA (2002) Transglutaminase bonds in neurofibrillary tangles and paired helical filament tau early in Alzheimer's disease. Neurochem Int 40:17-30.

Steffan JS, Kazantsev A, Spasic-Boskovic O, Greenwald M, Zhu YZ, Gohler H, Wanker EE, Bates GP, Housman DE, Thompson LM (2000) The Huntington's disease protein interacts with p53 and CREB-binding protein and represses transcription. Proc Natl Acad Sci USA 97:6763-6768.

Uhl L, Schindler J (1987) Transglutaminase activity and embryonal carcinoma cell differentiation. Exp Cell Biol 55:28-33.

Vonsattel JP, Myers RH, Stevens TJ, Ferrante RJ, Bird ED, Richardson EP Jr (1985) Neuropathological classification of Huntington's disease. J Neuropathol Exp Neurol 44:559-577. 